\title{
Development of Tandem Amorphous/Microcrystalline Silicon Thin-Film Large-Area See-Through Color Solar Panels with Reflective Layer and 4-Step Laser Scribing for Building-Integrated Photovoltaic Applications
}

\author{
Chin-Yi Tsai ${ }^{1}$ and Chin-Yao Tsai ${ }^{2}$ \\ ${ }^{1}$ Department of Applied Physics, National University of Kaohsiung, Kaohsiung 811, Taiwan \\ ${ }^{2}$ Auria Solar, Da-Ye 1st Road 9, Sinshih, Tainan 74146, Taiwan \\ Correspondence should be addressed to Chin-Yi Tsai; chinyitsai@hotmail.com
}

Received 14 June 2014; Accepted 2 July 2014; Published 20 July 2014

Academic Editor: Chien-Jung Huang

Copyright ( 2014 C.-Y. Tsai and C.-Y. Tsai. This is an open access article distributed under the Creative Commons Attribution License, which permits unrestricted use, distribution, and reproduction in any medium, provided the original work is properly cited.

In this work, tandem amorphous/microcrystalline silicon thin-film large-area see-through color solar modules were successfully designed and developed for building-integrated photovoltaic applications. Novel and key technologies of reflective layers and 4step laser scribing were researched, developed, and introduced into the production line to produce solar panels with various colors, such as purple, dark blue, light blue, silver, golden, orange, red wine, and coffee. The highest module power is $105 \mathrm{~W}$ and the highest visible light transmittance is near $20 \%$.

\section{Introduction}

Building-integrated photovoltaic (BIPV) is an important application area for photovoltaic industry and commerce $[1,2]$. It not only broadens and expands the usages for photovoltaic (PV) applications but also makes solar electricity more accessible and integrated to our daily lives. In BIPV applications, photovoltaic modules or panels are fabricated as an integral part of building materials, such as windows, skylights, facades, roof covers, and exterior walls. As a result, BIPV is an ideal solution for utilizing solar electricity while maintaining buildings' architecture functions and aesthetics at the same time. However, the current mainstream commercial PV modules are made from single-crystalline or multicrystalline silicon wafers. It would be very difficult or even impossible to tailor their functions and configurations for various BIPV applications, for example, the see-through function for BIPV windows or skylights. In addition, the production of the wafer-based silicon PV modules comprises different and separate processes for polysilicon materials, wafers, cells, and modules; it could be rather involved to commercially coordinate theses different production procedures and customize their functions or configurations for designated specifications required by various BIPV applications. On the contrary, material/cell/module manufacture processes are usually integrated into one production line for thin-film solar modules. As a result, it will be relatively easier to modify these manufacture processes to commercially customize the functions or configurations of solar modules; in particular, different types of large-area substrates, such as glass, plastic, ceramic, graphite, or metal, could be employed for thin-film solar modules to meet various BIPV specifications.

Currently, there are three major types of thin-film solar cells: silicon, cadmium telluride (CdTe), and copper indium gallium diselenide (CIGS). The efficiency of CdTe and CIGS thin-film solar cells could still contend with the waferbased silicon ones. Nevertheless, they use either precious metals such as In or toxic and hazardous metals such as Cd; certain questions and concerns still exist for their large-scale applications. Particularly, the $n$-type cadmium sulfide (CdS) used by both CdTe and CIGS thin-film solar cells contains 


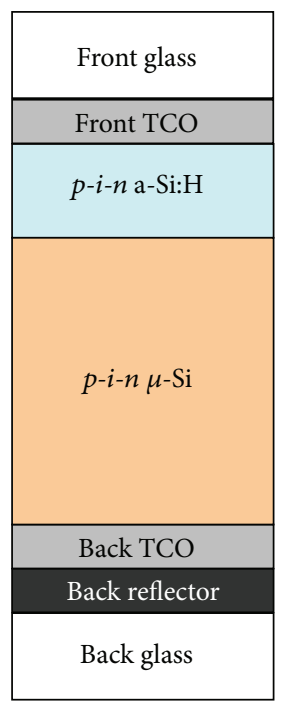

(a)

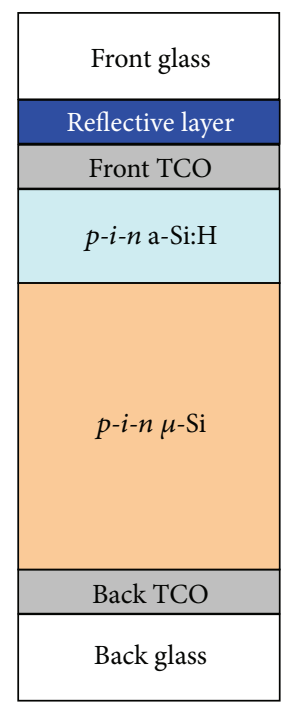

(b)

FIGURE 1: Schematic diagrams of a thin-film tandem amorphous/microcrystalline silicon solar cell of (a) a regular solar module and (b) a see-through color BIPV module.

the Cd element which remains a safety issue for their BIPV applications. Therefore, it is generally believed that silicon thin-film solar cell still has its certain advantages for BIPV applications. Moreover, it is worth mentioning that thinfilm silicon solar cells generally have a lower temperature coefficient and better low light performance. For PV systems with the same value of power of kilowatt $(\mathrm{kW})$, thin-film silicon ones could generate higher energy yield of kilowatthour $(\mathrm{kWh})$. In other words, PV systems of thin-film silicon usually could generate 5 to 10 percent more electricity than other types of systems due to their lower temperature coefficient and better low light performance.

Due to the demand for specific BIPV applications, there exist some conventional methods of making BIPV panels to appear with a specifically designed color. These conventional methods include the direct attachment of an organic color film outside the module, the spray or coating of color paint on the front glass, and the utilization of a dyed front glass. These conventional methods are impractical and have their limitations and problems for commercial BIPV products. For example, organic color films and paints are usually not very durable and thus could not be compatible with the 20to 25-year warranty associated with solar modules. Dyed front glass usually reflects too much incident sunlight which will make solar modules suffer enormous optical losses and thus have worse efficiency. From commercial consideration, additional materials incurred by these conventional methods are simply not very cost effective. As a result, in this work, many innovative technologies are researched, developed, and introduced into the production line of the large-area tandem amorphous/microcrystalline silicon thin-film solar module for BIPV applications. These novel and key technologies, including reflective layers and 4-step laser scribing, are not only compatible with the existing manufacture processes but also very cost effective. They were successfully introduced into the production line to manufacture BIPV panels with various colors, such as purple, dark blue, light blue, silver, golden, orange, red wine, and coffee. The details of these technologies and the resulted products will be discussed in what follows.

\section{Technologies}

In this work, the tandem amorphous/microcrystalline (also called as "micromorph") silicon thin-film solar modules are produced from the $60 \mathrm{MW}$ production line of Auria Solar [3-10]. The structure of a regular cell in tandem amorphous/microcrystalline silicon thin-film solar modules is schematically shown in Figure 1(a). In general, the thickness of the front and back glasses is about $3.2 \mathrm{~mm}$, the back reflector $0.5 \mathrm{~mm}$, the a-Si:H cell layer $300 \mathrm{~nm}$, the $\mu$-Si cell layer $1400 \mathrm{~nm}$, the back TCO $1500 \mathrm{~nm}$, and the front TCO $1800 \mathrm{~nm}$. In contrast, the structure of a see-through color BIPV module is schematically shown in Figure 1(b), where the back reflector in a regular cell will be dispelled for the purpose of see-through. In addition, a front reflector, named as the "reflective layer" in this work, will be added onto the front-glass substrate to reflect a certain part of spectrum of the incident sunlight and consequently make the solar panel appear with a specifically designed color. The thickness of the reflective layer is usually several tens of nanometers according to the specification of the designed color panels.

The manufacture processes of these modules are briefly outlined in Figure 2, in which a front-glass substrate is grown with a reflective layer first. After the growth of the reflective layer, the first laser scribing process was applied onto the layer to open a "color window" for preventing the reflectively layer from blocking the subsequent laser scribing processes in which the laser beams go through the glass into the scribed material. The low-pressure chemical vapor 


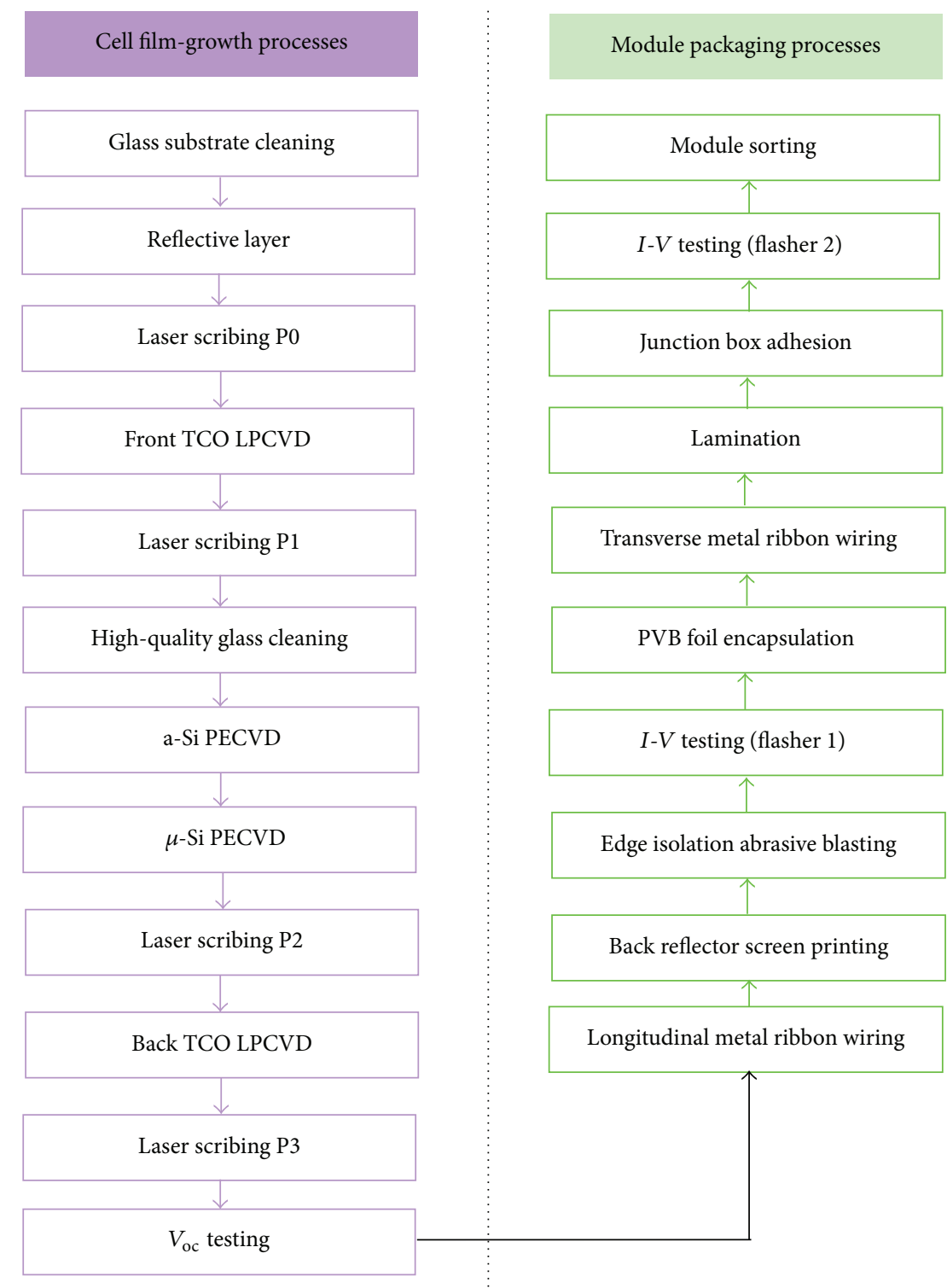

FIGURE 2: Schematic diagram illustrating the flow of manufacture processes of thin-film tandem amorphous/microcrystalline silicon seethrough color BIPV modules.

deposition (LPCVD) front TCO film was then grown and the second laser scribing process was applied on it to define the physical boundaries of cells. Subsequently, the plasmaenhanced chemical vapor deposition (PECVD) hydrogenrich amorphous silicon (a-Si:H) and microcrystalline silicon $(\mu-\mathrm{Si})$ thin film was grown and the third laser scribing process was applied on it. Afterwards, the LPCVD back TCO film was grown and the fourth laser scribing process was applied on it to form the basic structure of each solar cell and serially connect them to comprise a solar module. At this stage, the panel is in fact a fully functioned photovoltaic device; yet it needs to be further packaged to become a commercial photovoltaic module. The module packaging processes involved the metal ribbon wiring, abrasive blasting edge isolation, PV foil encapsulation, lamination, and junction-box adhesion. The size of a panel is $1.3 \mathrm{~m} \times 1.1 \mathrm{~m}$ which is determined by the area of the glass substrate. A module is usually laser-scribed into 99 cells and its output voltage is regularly about $100 \mathrm{~V}$.

To produce modules with see-through function and various colors appearance, many technologies were researched, developed, and introduced into the production line. These technologies are required to ensure that the color appearance is uniformly observed of the produced modules. Furthermore, the color appearance is required to maintain its uniformity on the whole area of each individual module. The throughput and yield in every production process is also demanded not to be compromised when introducing these technologies into the production line. These key technologies will be, respectively, discussed in what follows.

2.1. Reflective Layer. As shown in Figure 1, in order to achieve the see-through function for BIPV applications, the back 
reflective layer (usually called as the "back reflector") was removed from the regular thin-film solar modules. On the other hand, the front reflective layer was introduced between the front glass and the front TCO film to reflect parts of the incident sunlight and thus to make the panels appear with a specifically designed color. There exist some conventional methods of making BIPV panels appear with a specifically designed color. These conventional methods include the direct attachment of an organic colored film outside the module, the spray or coating of color paint on the front glass, and the utilization of a dyed front glass. These conventional methods are impractical and have their limitations and problems for commercial BIPV products. On the contrary, the reflective layer overcomes all these problems and limitations and thus makes the color BIPV panels much more cost effective for commercial products.

The reflective index of the reflective layer material and the thickness of the reflective layer should be carefully selected and designed to cooperate with the TCO and light-absorbing films to make BIPV panels appear with a specifically designed color. However, a material with high bandgap energy is normally preferred in order to minimize its light absorption. Therefore, hydrogen-rich amorphous silicon carbide (a$\mathrm{SiC}: \mathrm{H})$ grown by PECVD was selected as the material for the reflective layer in this work because it can be fabricated by the same PECVD equipment of growing a-Si:H and $\mu$ $\mathrm{Si}$. a-SiC:H has a higher bandgap energy than a-Si:H and $\mu$ $\mathrm{Si}$, and it also can form a good material interface between the a-SiC:H reflective layer and the $\mathrm{ZnO}$ TCO film. This will certainly minimize the cost and complexity of the overall color BIPV manufacture processes. It should be noted that other materials (except PECVD-grown a-Si:H, $\mu$-Si, and a$\mathrm{SiC}: \mathrm{H})$ could potentially be utilized as the reflective layer, and their performance might be possibly better than a-SiC:H. However, they could also incur additional cost and further complexity in manufacture processes when introducing them into the production lines.

The thickness of the reflective layer is several tens of nanometers. For such a nanosize film, its quality and uniformity need to be closely monitored and controlled in order to ensure that its designated reflective index and film thickness would not be compromised to yield the different color appearance. Of course, ideally, the reflective layer should be as thin as possible to minimize the light absorption. However, the film uniformity of the reflective layer is very difficult to be precisely controlled when the film thickness is at several tens of nanometers, especially for large-area thinfilm solar panels. If the thickness of the reflective layer is not carefully controlled, solar panels will suffer severe problems of film nonuniformity and thus different solar panels will have different colors. In the worst case, different colors will even appear at a single solar panel that makes the product unsuitable for BIPV applications.

2.2. 4-Step Laser Scribing. In general, a large-area thin-film solar panel requires 3 -step laser scribing processes (named as $\mathrm{P} 1, \mathrm{P} 2$, and P3) to partition the whole panel into several cells and to serially connect cells into a module, as schematically shown in Figure 3. The P1 process scribes the front TCO film and thus defines the boundary of each cell. The P2 process scribes the light-absorbing film and the $\mathrm{P} 3$ process scribes the back TCO film and light-absorbing film. The widths of the laser scribing lines are generally determined by the spot sizes of the laser beams and usually several tens of micrometers. Since these 3-step laser scribing processes cannot be overlapped with each other, the areas occupied by them are called the "dead zones" which indicate no photocurrent being contributed from them. In this work, the laser scribing system employed diode-pumped solid-state lasers (DPSSL) with wavelengths of $355 \mathrm{~nm}$ for P1 and $532 \mathrm{~nm}$ for P2 and P3 of the 3-step laser scribing, respectively. The lasers were operated through the glass in order to minimize the scribing debris to contaminate the lenses of the laser system. As a result, if the reflective layer is grown first on the glass substrate, parts of the laser beams used in scribing the TCO and light-absorbing films will be reflected or scattered by the reflective layer. The reflection and scattering of the laser beams by the reflective layer will cause the scribing lines to be nonuniform or even broken at some places.

In order to solve this problem, an innovative method of 4-step laser scribing was devised in this work, as shown schematically in Figure 4. After the reflective layer was grown on the glass substrate, a laser scribing was employed to scribe lines on the reflective layer. The width of these lines is larger than the dead zone of the 3-step laser scribing, as shown in Figure 5. As a result, these scribing lines will generate "windows" (which are denominated as "color windows" in this work) to avoid the reflection and scattering of the laser beams in the subsequent laser scribing processes. The laser scribing for color windows combined with 3-step ones for TCO and light-absorbing films are hence called the 4-step laser scribing process. It should be noted that the laser scribing for color windows is denominated as the $\mathrm{P} 0$ process in order to preserve the conventional designation of $\mathrm{P} 1, \mathrm{P} 2$, and $\mathrm{P} 3$ processes.

2.3. Pen-Type Junction Box. For Auria's regular solar panels, the junction box is box type one and located at the center of the upper part of the panel which of course is unacceptable to be used in the see-thorough BIPV panel. In order to achieve the see-through function, box-type junction boxes used in the regular solar panel were replaced by pen-type ones. The pen-type junction boxes are located at the edge of the panel to minimize their visual obstacle for the see-through function. As a result, the transverse metal wiring in the manufacture processes needs to be rearranged in order to employ the pen-type junction boxes. However, it should be noted that conventional box-type junction boxes will still be used if the see-through function is not required for specific applications.

\section{Results and Discussion}

The see-through panels without the reflective layer will appear from light brown to dark brown according to 


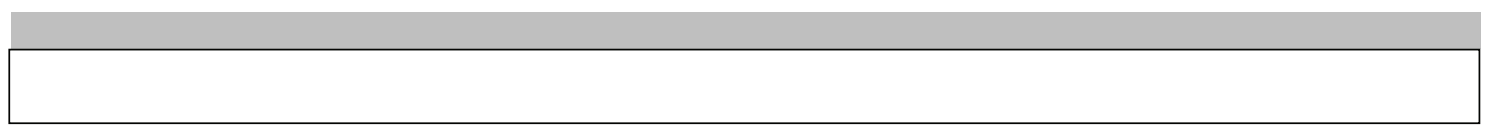

(a)

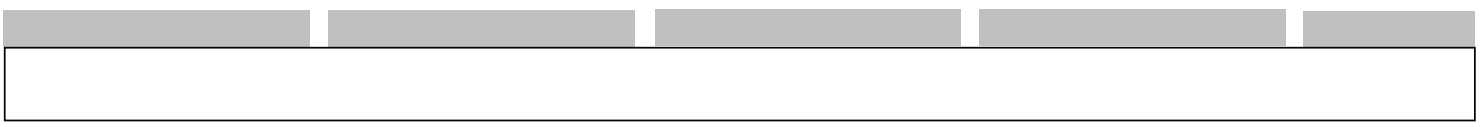

(b)

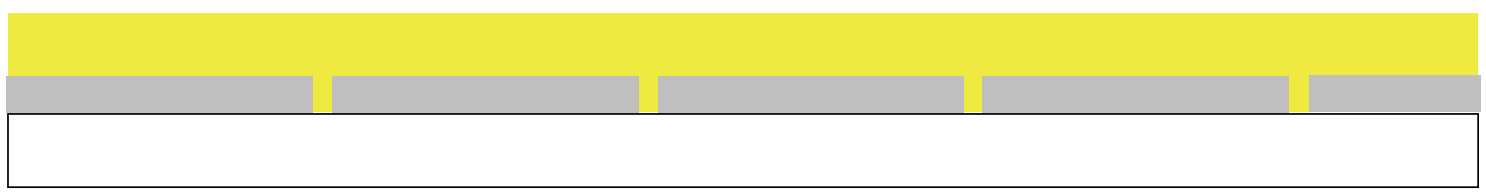

(c)

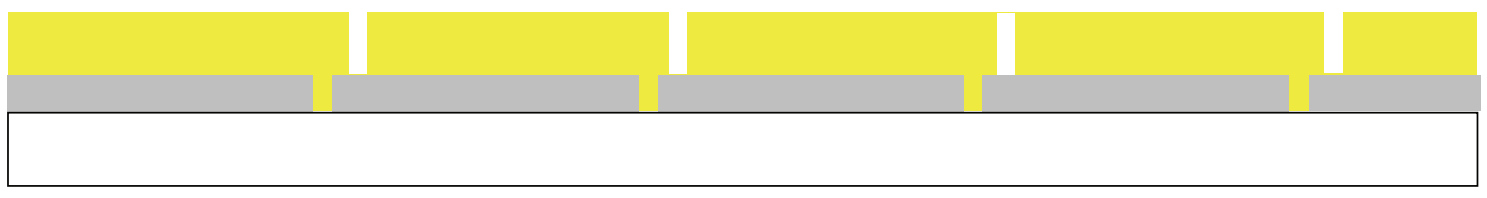

(d)

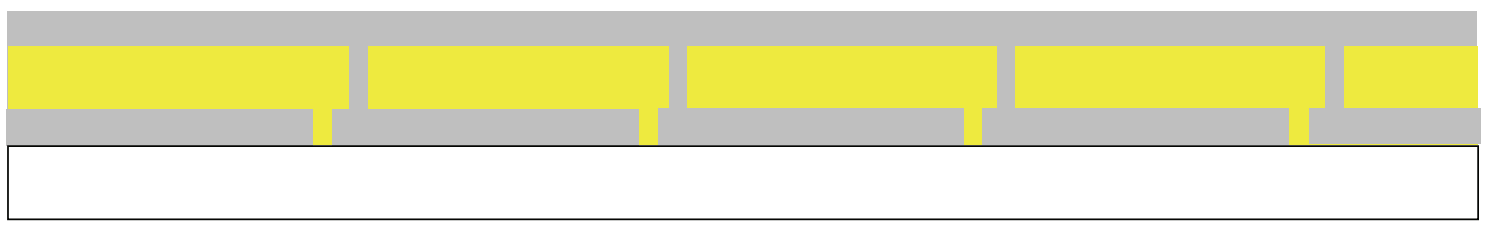

(e)

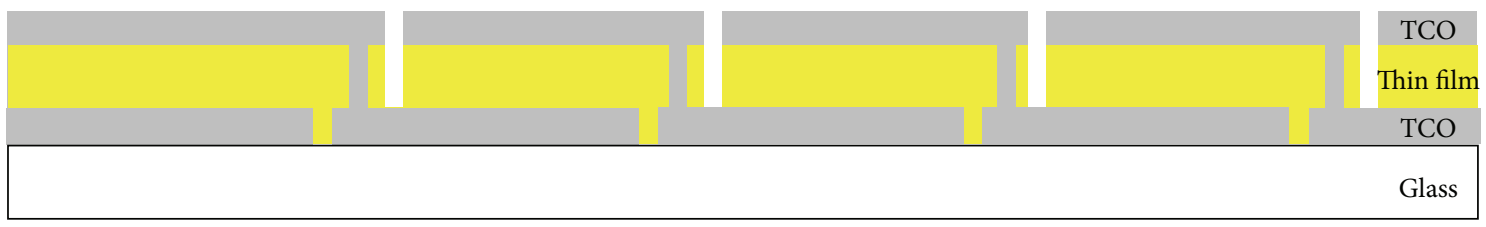

(f)

FIGURE 3: 3-step laser scribing processes of a regular thin-film tandem amorphous/microcrystalline silicon solar module. The schematic diagrams illustrate (a) the growth of the TCO film onto the glass substrate, (b) the first laser scribing process P1 on the TCO film, (c) the growth of the light-absorbing film onto the TCO film, (d) the second laser scribing process P2 on the light-absorbing film, (e) the growth of the TCO film onto the light-absorbing film, and (f) the third laser scribing process P3 on the TCO film and the light-absorbing film.

the variations of the thickness of the amorphous/microcrystalline silicon light-absorbing films, as shown in Figure 6. With the technologies of the reflective layer and the 4-step laser scribing, eight different colors of purple, dark blue, light blue, silver, gold, orange, red, and coffee tandem amorphous/microcrystalline silicon thin-film see-through solar modules were successfully designed and mass-produced in Auria's $60 \mathrm{MW}$ production line, as shown in Figure 7. It should be noted that the see-through function is defined as viewing from the back glass through the front glass. If viewing from the front glass through the back glass, the light reflection from the reflective layer will dominate and the see-through function is then almost diminished as demonstrated in Figure 7. The BIPV solar panels produced by Auria are fully commercialized. They have passed not only the TÜV IEC61646 and IEC-61730 certifications but also the IEC-61701 salt mist test. Examples of their commercial installations are given in Figure 8.

The output power $\left(P_{\mathrm{mpp}}\right)$, voltage $\left(V_{\mathrm{mpp}}\right)$, current $\left(I_{\mathrm{mpp}}\right)$ at the maximum peak power (mmp), open-circuit voltage $\left(V_{\mathrm{oc}}\right)$, short-circuit current $\left(I_{\mathrm{sc}}\right)$, and the transmittance of the visible light for these see-through BIPV modules with different colors of purple, dark blue, light blue, silver, gold, orange, red, and coffee are given in Table 1. A best-recorded regular solar module of black brown without the see-through function is also listed for the purpose of comparison. All the color modules have approximately similar open-circuit voltages, but their short-circuit currents vary significantly. The silver and gold modules have the worst output power. It should be noted that the short-circuit current has no direct correlation with the transmittance of the visible light measured at the side of the back glass. The exceptionally low output power from 


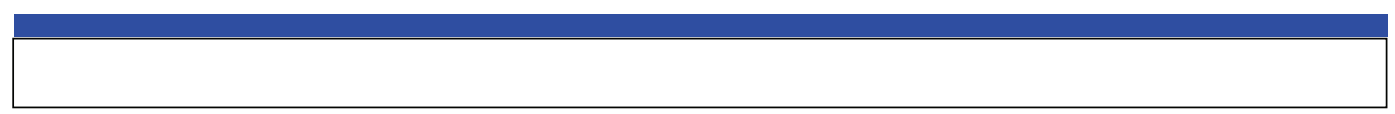

(a)

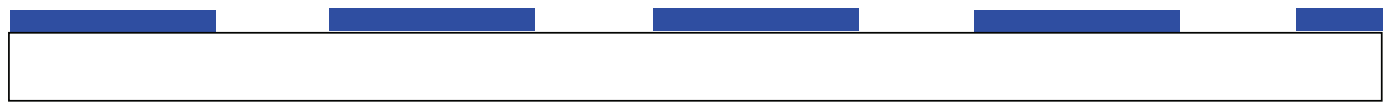

(b)

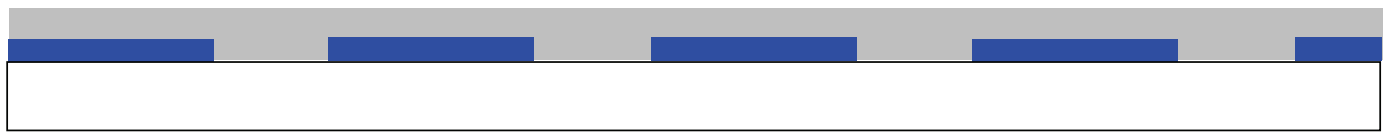

(c)

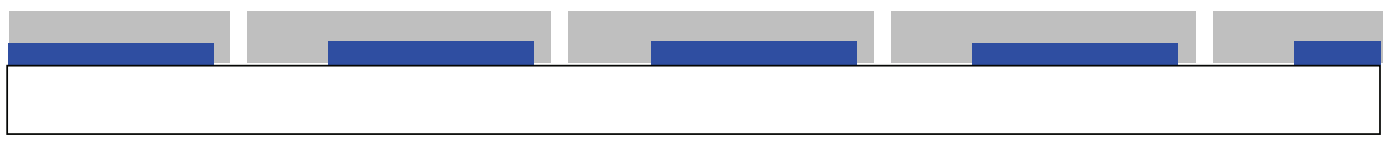

(d)

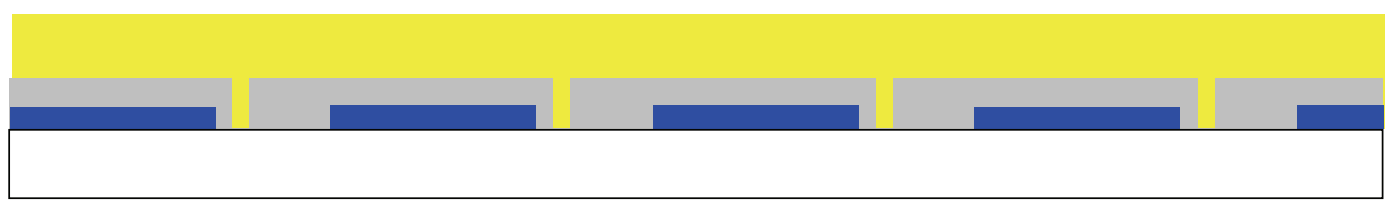

(e)

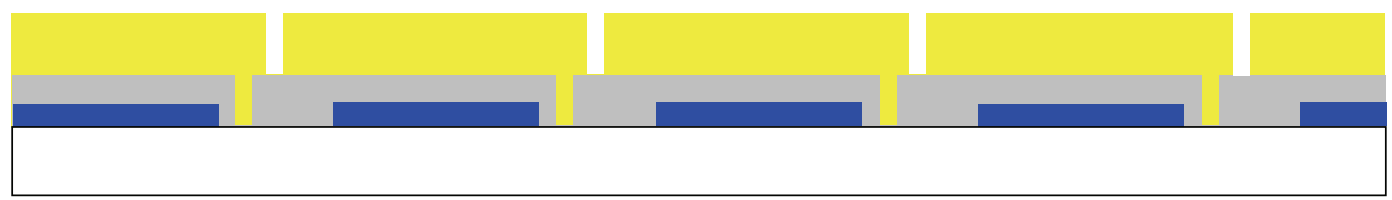

(f)

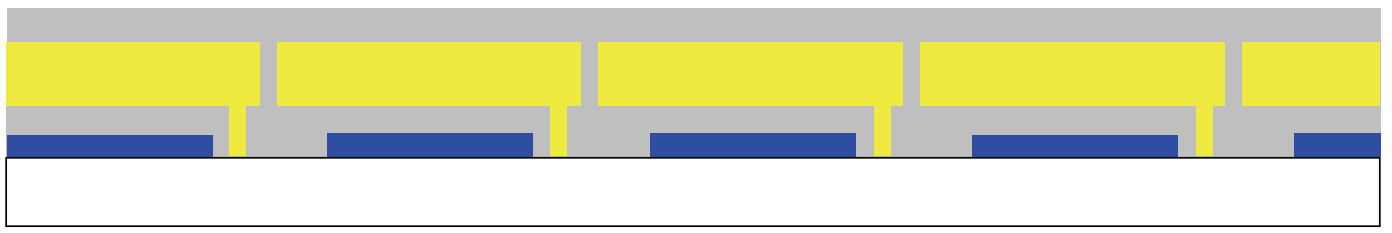

(g)

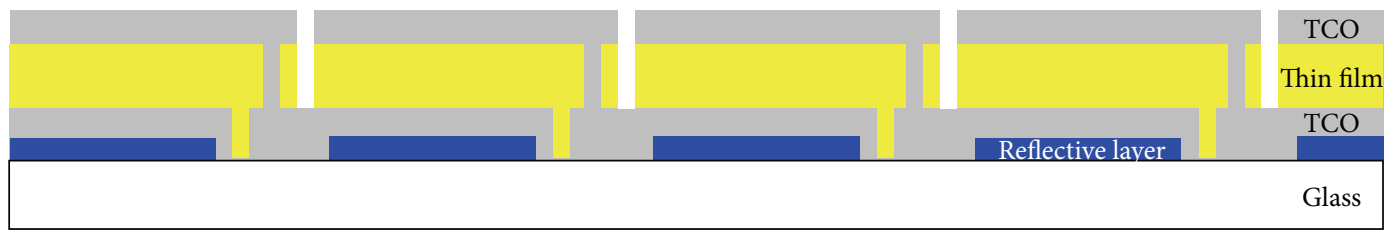

(h)

FIGURE 4: 4-step laser scribing processes of a thin-film tandem amorphous/microcrystalline silicon color see-through BIPV solar module. The schematic diagrams illustrate (a) the growth of the reflective layer onto the glass substrate, (b) the first laser scribing process P1 on the reflective layer, (c) the growth of the TCO film onto the reflective layer, (d) the second laser scribing process P2 on the TCO film, (e) the growth of the light-absorbing film onto the TCO film, (f) the third laser scribing process P3 on the light-absorbing film, (g) the growth of the TCO film onto the light-absorbing film, and (h) the fourth laser scribing process P4 on the TCO film and the light-absorbing film.

the silver and gold modules can be examined by their spectral reflectivity, as shown in Figure 9. The maximal reflected wavelengths were located at $465 \mathrm{~nm}$ and $625 \mathrm{~nm}$ for the silver and gold modules, respectively. The average magnitudes of the reflectivity of the silver and gold modules are almost twice of those of the dark blue and purple ones. As a result, the output power of the silver and gold modules is almost half of that of the dark blue and purple ones. This example just illustrates that although the thickness of the reflective layer is just several tens of nanometers, its effect on the performance 


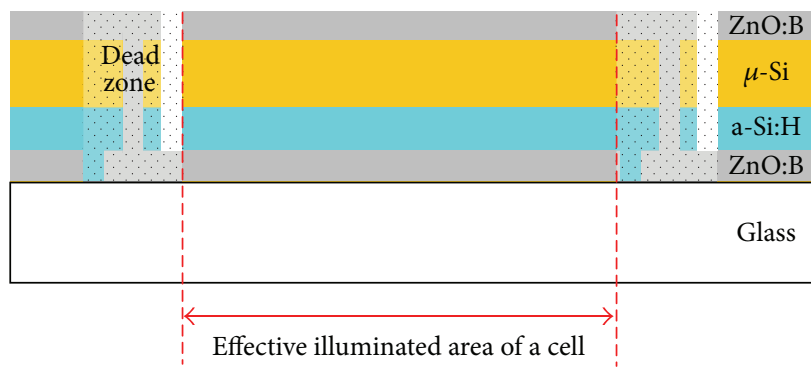

(a)

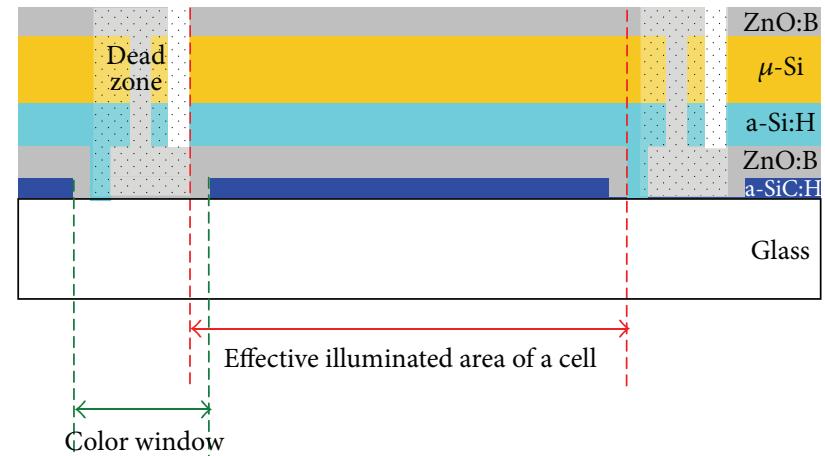

(b)

FIGURE 5: Schematic diagrams of a thin-film tandem amorphous/microcrystalline silicon solar module of (a) a regular solar module and (b) a see-through color BIPV module.

TABLE 1: The output power $\left(P_{\mathrm{mpp}}\right)$, voltage $\left(V_{\mathrm{mpp}}\right)$, current $\left(I_{\mathrm{mpp}}\right)$ at the maximum peak power $(\mathrm{mmp})$, open-circuit voltage $\left(V_{\mathrm{oc}}\right)$, short-circuit current $\left(I_{\mathrm{sc}}\right)$, and the transmittance of the visible light for see-through BIPV modules with different colors of purple, dark blue, light blue, silver, gold, orange, red, and coffee. A best-recorded regular solar module of black brown without the see-through function is listed for the purpose of comparison.

\begin{tabular}{lcccccc}
\hline Solar module & $P_{\mathrm{mpp}}(\mathrm{W} ; \pm 3 \%)$ & $V_{\mathrm{mpp}}(\mathrm{V})$ & $I_{\mathrm{mpp}}(\mathrm{A})$ & $V_{\mathrm{oc}}(\mathrm{V})$ & $I_{\mathrm{sc}}(\mathrm{A})$ & Transmittance $(\% ; 400 \sim 800 \mathrm{~nm})$ \\
\hline Purple & 75 & 86.1 & 0.89 & 116.3 & 1.03 & 11.6 \\
Dark blue & 75 & 85.2 & 0.88 & 114.7 & 1.01 & 10.9 \\
Light blue & 60 & 89.9 & 0.66 & 117.0 & 0.76 & 9.5 \\
Silver & 45 & 89.8 & 0.51 & 117.5 & 0.61 & 9.5 \\
Gold & 45 & 91.6 & 0.51 & 116.5 & 0.58 & 6.3 \\
Orange & 80 & 97.2 & 0.84 & 126.3 & 0.94 & 19.9 \\
Red & 90 & 95.1 & 0.95 & 124.8 & 1.06 & 16.2 \\
Coffee & 105 & 100.4 & 1.04 & 129.0 & 1.24 & 5.9 \\
Regular & 151 & 132.5 & 1.14 & 171.5 & 1.25 & 0 \\
\hline
\end{tabular}

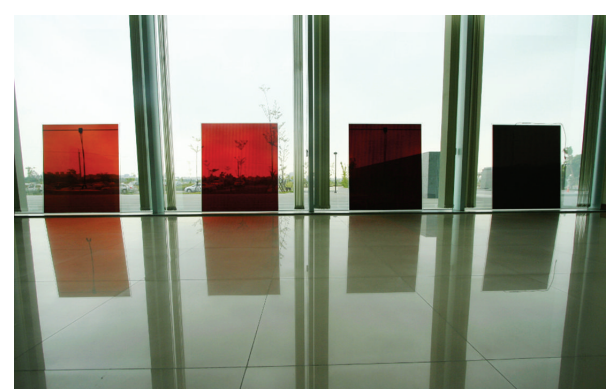

FIGURE 6: 4 Auria's silicon thin-film see-through BIPV modules of different film thicknesses and without the reflective layers.

of the color modules is nevertheless enormously significant. It should be mentioned that the performances of all the color modules presented here have not fully optimized yet, if compared to those of regular modules, especially to the firstrate regular module as given in Table 1 . It should be noted that the see-through color thin-film modules without the back reflective layer will certainly lose a significant amount

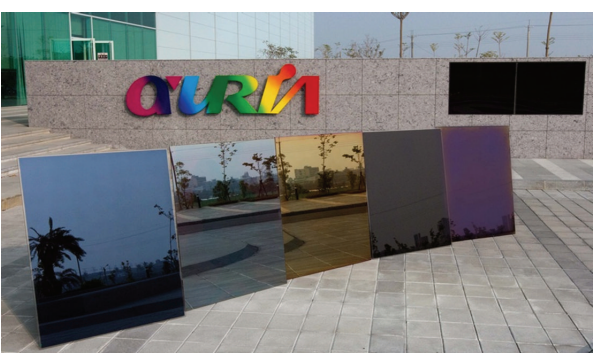

FIgURE 7: 4 Auria's silicon thin-film see-through BIPV modules of different colors: dark blue, silver, gold, coffee, and purple from left to right.

of photocurrent in conjunction with the light-reflection loss from the reflective layer. In short, the overall manufacture parameters need to be carefully modified and properly fine-tuned to accommodate the optical and electrical properties changes from the introduction of the reflective layer on the color modules. 


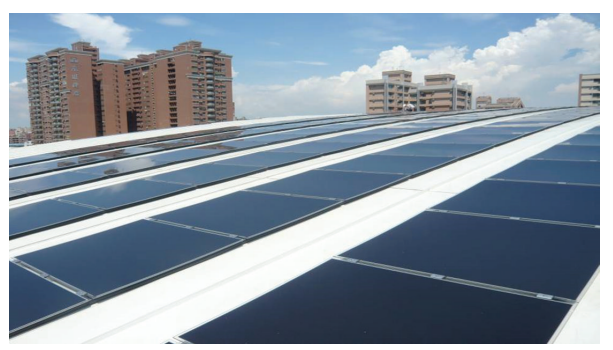

(a)

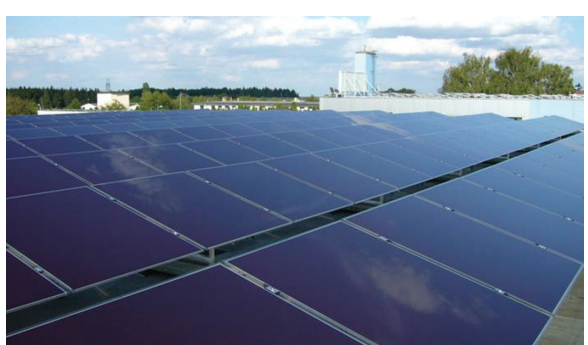

(b)

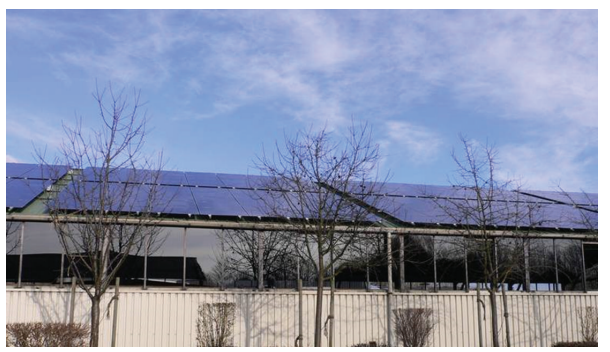

(c)

Figure 8: The installations of the Auria dark blue BIPV modules in 3 different locations: (a) $20.7 \mathrm{~kW}$ in Kaohsiung, Taiwan, (b) $78 \mathrm{~kW}$ in Sofia, Bulgaria, and (c) $50 \mathrm{~kW}$ in Dortmund, Germany.

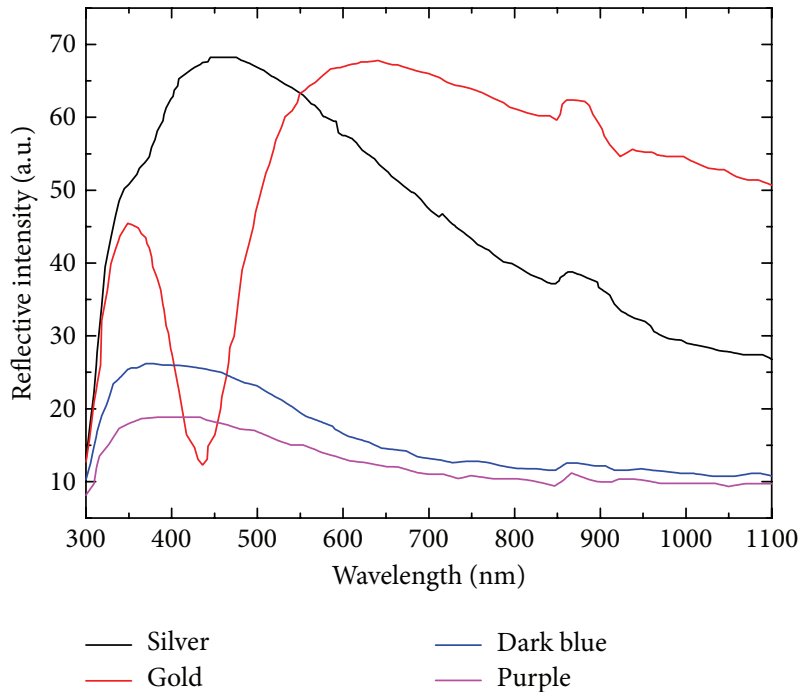

FIGURE 9: The spectrums of the reflective light intensity from thinfilm tandem amorphous/microcrystalline silicon see-through BIPV modules of different colors.

\section{Conclusion}

In this work, tandem amorphous/microcrystalline silicon thin-film large-area see-through color solar modules were successfully designed and developed for building-integrated photovoltaic applications. Novel and key technologies of reflective layers and 4-step laser scribing were researched, developed, and introduced into the production line to produce solar panels with various colors, such as purple, dark blue, light blue, silver, golden, orange, red wine, and coffee.
The highest module power is $105 \mathrm{~W}$ and the highest visible light transmittance is near $20 \%$.

\section{Conflict of Interests}

The authors declare that there is no conflict of interests regarding the publication of this paper.

\section{Acknowledgments}

The authors would like to thank the help from all the colleagues in Auria Solar. This work is partially funded by the Bureau of Energy of Ministry of Economic Affairs and the National Science Council of Taiwan.

\section{References}

[1] P. Eiffert and G. J. Kiss, Building-Integrated Photovoltaic Designs for Commercial and Institutional Structures: A Source Book for Architect, National Renewable Energy Laboratory, Golden, Colo, USA, 2000.

[2] S. Roberts and N. Guariento, Building Integrated Photovoltaics, Birkhäauser, Berlin, Germany, 2009.

[3] H. Keppner, J. Meier, P. Torres, D. Fischer, and A. Shah, "Microcrystalline silicon and micromorph tandem solar cells," Applied Physics A: Materials Science and Processing, vol. 69, no. 2, pp. 169-177, 1999.

[4] A. Shah, J. Meier, E. Vallat-Sauvain et al., "Microcrystalline silicon and "micromorph" tandem solar cells," Thin Solid Films, vol. 403-404, pp. 179-187, 2002.

[5] J. Meier, S. Dubail, S. Golay et al., "Microcrystalline silicon and the impact on micromorph tandem solar cells," Solar Energy Materials and Solar Cells, vol. 74, no. 1-4, pp. 457-467, 2002. 
[6] A. V. Shah, H. Schade, M. Vanecek et al., "Thin-film silicon solar cell technology," Progress in Photovoltaics: Research and Applications, vol. 12, no. 2-3, pp. 113-142, 2004.

[7] K. Yamamoto, M. Yoshimi, Y. Tawada, Y. Okamoto, and A. Nakajima, "Thin film Si solar cell fabricated at low temperature," Journal of Non-Crystalline Solids, vol. 266-269, pp. 1082-1087, 2000.

[8] K. Yamamoto, M. Yoshimi, Y. Tawada et al., "Large area thin film Si module," Solar Energy Materials and Solar Cells, vol. 74, no. 1-4, pp. 449-455, 2002.

[9] K. Yamamoto, A. Nakajima, M. Yoshimi et al., "A high efficiency thin film silicon solar cell and module," Solar Energy, vol. 77, no. 6, pp. 939-949, 2004.

[10] A. Nakajima, M. Gotoh, T. Sawada et al., "Development of thinfilm Si HYBRID solar module," Solar Energy Materials and Solar Cells, vol. 93, no. 6-7, pp. 1163-1166, 2009. 

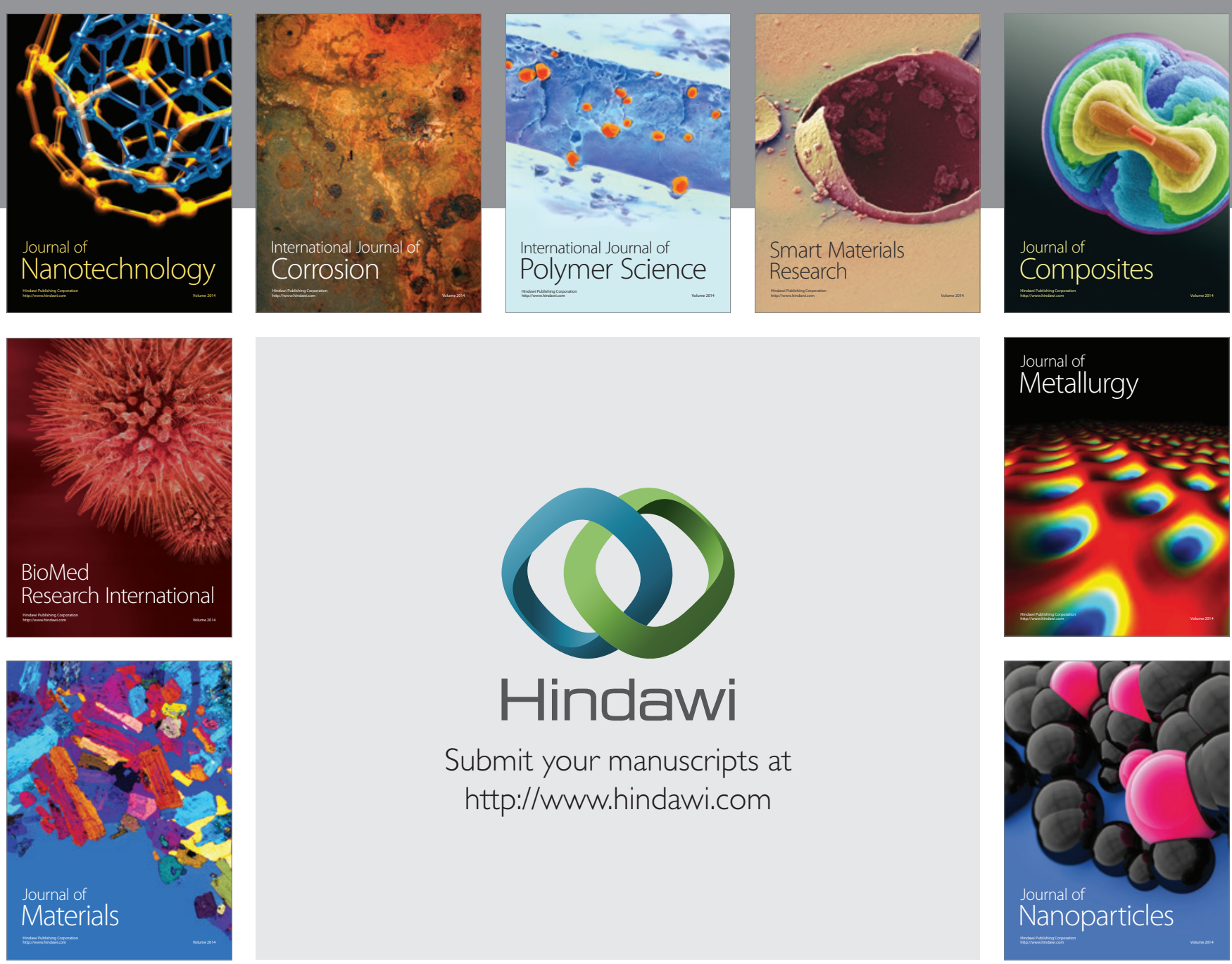

Submit your manuscripts at http://www.hindawi.com
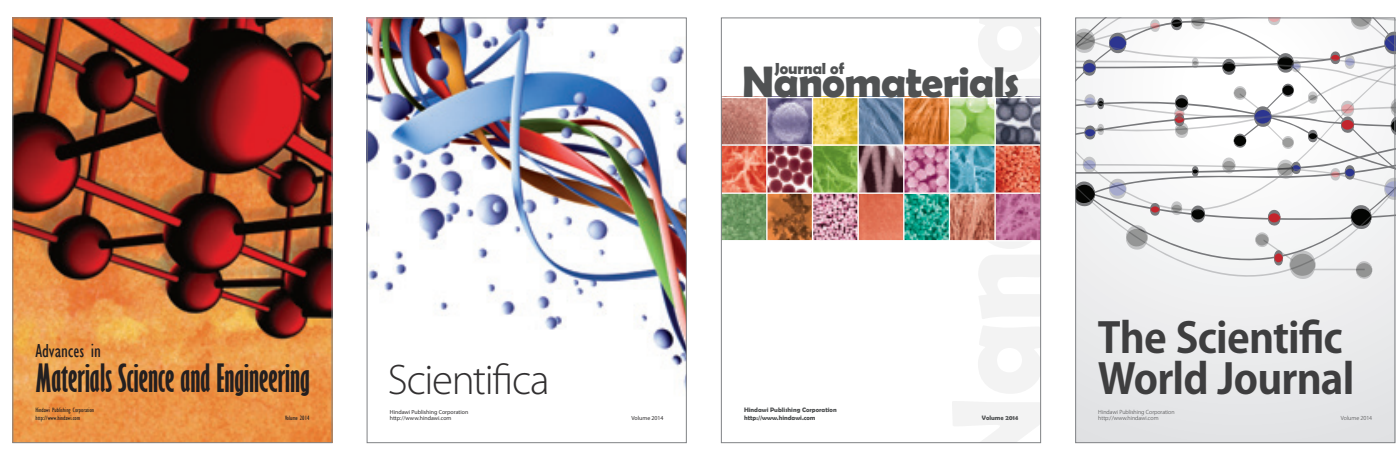

\section{The Scientific World Journal}
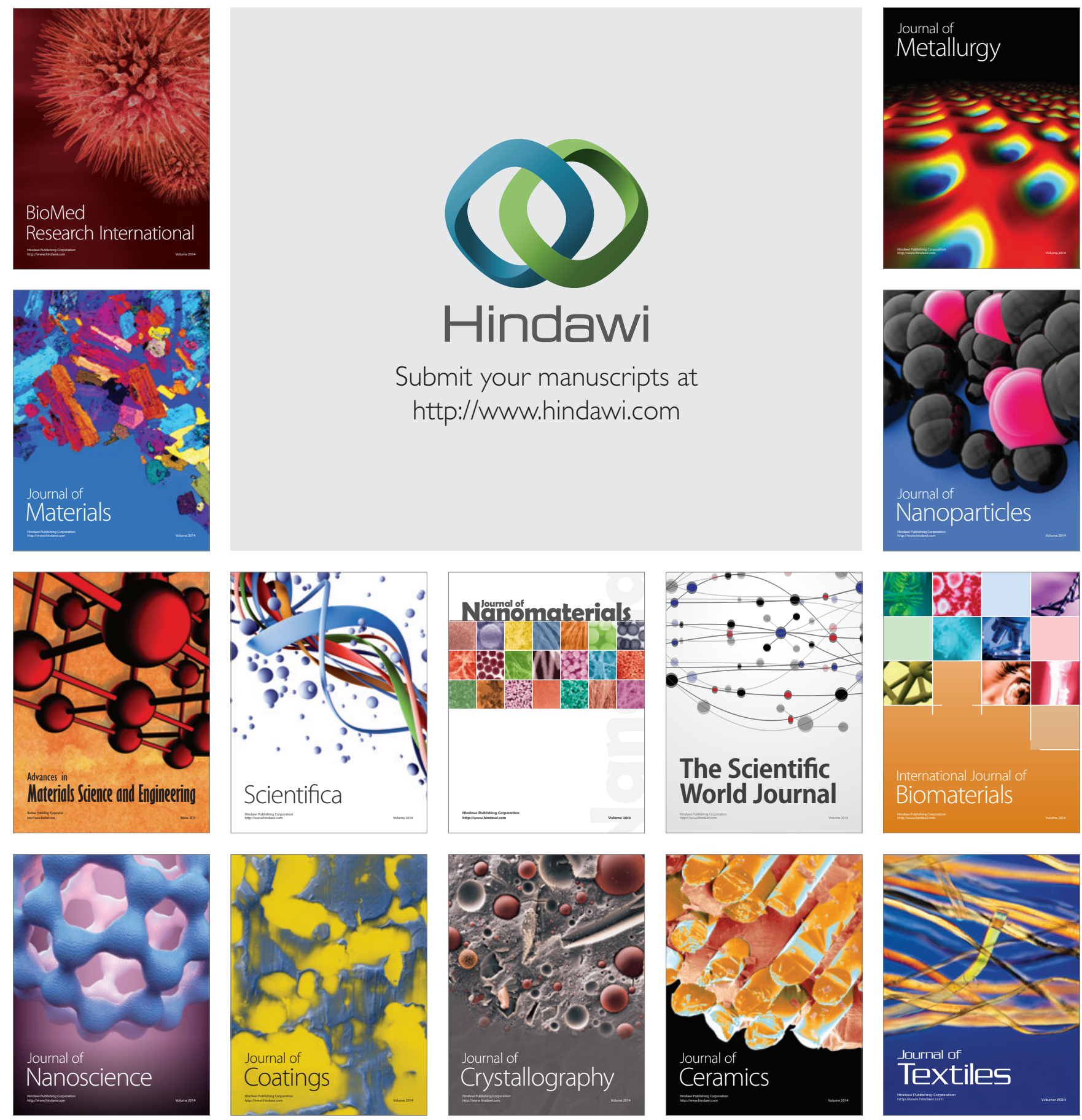